\title{
El Caso Mundial y El Caso Criminal, cabeceras del nuevo semanario de sucesos que surge en España tras la desaparición de El Caso (1952-1987)
}

Recibido: 7 de diciembre de 2018

Aceptado: 20 de marzo de 2019

Publicado: 24 de junio de 2019
Rosa Rodríguez Cárcela

rmaria.rodriguez@juntadeandalucia.es

Grupo GREHCCO de la Universidad de Sevilla (España)

Resumen: El artículo hace un estudio de El Caso Mundial y El Caso Criminal, cabeceras del nuevo semanario de sucesos que surgió en España tras la desaparición de El Caso (Madrid, 1952-1987) y editado por el empresario y periodista Joaquín Abad. Apenas se han realizado investigaciones sobre este periódico que vino a llenar el vacío dejado por El Caso de Eugenio Suárez. Las fuentes consultadas ponen de manifiesto que se trató realmente de una nueva publicación periodística, compartiendo algunas similitudes, pero diferente. No se puede considerar, por tanto, una segunda etapa. Se imprimió y distribuyó desde Almería durante diez años (1987-1997), aunque tenía difusión nacional. Se analiza su estilo informativo, contenidos, directores y las causas que motivaron su cierre el 24 de septiembre de 1997.

Palabras clave: Periodismo de sucesos, prensa especializada, El Caso, crímenes, historia del periodismo en España, estilo periodístico.

Abstract: The paper analyses "El Caso Mundial" and "El Caso Criminal", both of them
event newspapers that emerged in Spain after the disappearance of "El Caso" (Madrid,
1952-1987), and was published by the businessman and journalist Joaquín Abad. Few
research has been done on this newspaper that came to fill the gap left by "El Caso",
directed by Eugenio Suárez. The sources consulted show that it was really a newjournalistic
publication, similar to the original one, but different. Therefore, it cannot be considered
a second stage. It was printed and distributed from Almería for ten years (1987-1997),
although it had a national scope. His informative style, content, directors and the causes
that led to its completion on September 24, 1997.

Key words: Event Journalism, Specialized Press, El Caso, Crimes, History of Journalism in Spain, Journalistic Style. 


\section{Introducción}

El semanario de sucesos español El Caso (fundado en Madrid por Eugenio Suárez en 1952) tuvo una duración de 35 años. El 29 de agosto de 1987 salía a la calle el último número de uno de los periódicos de mayor éxito en la España del siglo XX, ya que supuso un ejemplo de prensa popular rentable, con un gran número de lectores y revitalizó el periodismo de sucesos y de investigación. Esta publicación especializada marcó un antes y un después en la historia reciente del periodismo español, al divulgar noticias sobre crímenes y hechos delictivos que ningún otro medio se atrevió a publicar durante la dictadura de Francisco Franco. Supo zafarse hábilmente de la censura (aunque no sin problemas) y rompió con el silencio existente en torno a la difusión de los sucesos.

Desapareció del mercado de la prensa escrita tras haber llegado a la quiebra. Las causas que motivaron esta situación fueron tanto económicas (la competencia de otras incipientes empresas periodísticas) como derivadas de problemas familiares de Suárez que supusieron un alto coste para sus arcas. Aunque gozaba de un público fiel y de una tirada que se elevaba a los 142914 ejemplares, según la Oficina de Justificación de la Difusión, OJD ${ }^{1}$ (El Caso, 4/VII/1987), los gastos superaron a los ingresos y el negocio periodístico, antes rentable, acabó en la ruina.

Aprovechando esta coyuntura, Joaquín Abad, empresario y periodista que había sido su último director, puso en marcha un nuevo semanario de sucesos, similar en apariencia al anterior en cuanto a cabecera, formato y contenidos: el 12 de septiembre de 1987 sacaba al mercado El Caso Mundial, posteriormente se denominaría El Caso Criminal y finalmente El Caso. Dejó de editarse el 24 de septiembre de 1997, imprimiéndose por última vez en Almería. Continuó con el estilo marcado y, aunque era también un periódico rentable, las dificultades fueron incrementándose con el paso del tiempo, ya que la sociedad y los lectores no eran los mismos, la competencia de otros medios (especialmente la televisiva) era feroz, los costes de distribución y papel cada vez mayores y las costas judiciales derivadas de numerosos pleitos fueron muy elevadas.

Analizamos en este trabajo de investigación la puesta en marcha de un modelo de negocio periodístico basado en la información de sucesos, que toma como referencia una marca comercial El Caso. Las fuentes consultadas evidencian que la nueva publicación especializada que surgió no supuso el inicio de una segunda etapa del originario semanario de sucesos, puesto que la titularidad del mismo nunca pasó a manos de Joaquín Abad. Lo que sostenemos en este artículo es que en 1987 apareció otro periódico de sucesos diferente (de ámbito nacional, aunque editado en Almería) pero con unas cabeceras visualmente casi idénticas al creado en Madrid en 1952.

1 Empresa creada en España en el año 1964, formada por anunciantes, agencias y medios, viene certificando la difusión de las publicaciones periódicas (diarios y revistas) desde 1964 y sitios web en Internet desde 1997. Desde 2014 se denomina Información y Control de Publicaciones, S. A. 
En ese sentido, se deshace la idea (extendida en la mayoría de los medios de comunicación españoles) de que Abad compró la cabecera de Eugenio Suárez y se inició una segunda etapa de El Caso, publicándose semanalmente de forma ininterrumpida desde el 11 de mayo de 1952 al 24 de septiembre de 1997. No fue así. Su primer número no salió el siguiente sábado (5 de septiembre), sino el sábado posterior (día 12) con una nueva cabecera, El Caso Mundial (editado por Edial S. A.) y figuraba como No 1 . El último número de El Caso fue el 1843, correspondiente al 29 de agosto de 1987. Consideramos, con los datos obtenidos, que se trató de un periódico parecido (que tuvo sus méritos, fue rentable y contó con buenos profesionales), continuador de la línea marcada por el histórico semanario de sucesos.

\section{Metodología}

Los datos recogidos provienen de fuentes de primera mano, como son las de Juan Sánchez Rada (director adjunto de El Caso en su últimos años) y José Manuel Bretones (último director del semanario de sucesos de Joaquín Abad, editado en Almería), quien estuvo al frente del mismo desde 1992 a 1997 y también fue redactor jefe de 1989 hasta 1992.

Asimismo, hemos consultado en la Biblioteca Pública Provincial "Francisco Villaespesa" de Almería, en cuyos fondos² se encuentran ejemplares de El Caso Mundial (1987-1989), El Caso Criminal (del 20 de mayo de 1989 al 13 de agosto de 1994) y El Caso (del 20 de agosto de 1994 al 24 de septiembre de 1997).

Del mismo modo, se han efectuado consultas en la Biblioteca Nacional de Madrid y en la Hemeroteca Municipal de Madrid, instituciones que conservan colecciones incompletas del semanario de Joaquín Abad. Por último, se ha contactado con la Biblioteca de la Universidad CEU San Pablo de Madrid donde (a través del departamento de Proceso Técnico) nos han dado información relativa a la fecha del último número de El Caso original depositado en esta universidad privada.

Importantes fuentes documentales analizadas han sido tres facsímiles (a tamaño real) de El Caso, propiedad de la autora del artículo, de fechas 4 de julio de 1987; El Caso Mundial, del 3 de octubre de 1987 y del 4 de marzo de 1989. También las portadas escaneadas del último número de El Caso (No 1843, 29 de agosto de 1987) y del número 1 de El Caso Mundial (12 de septiembre de 1987), suministrados por Juan S. Rada; así como de la portada y contraportada escaneadas del último número de $E l$ Caso editado en Almería ( ${ }^{\circ} 2444$, del 24 de septiembre de 1997) y de la portada de $E l$

2 El Servicio de Información Bibliográfica y Referencia nos ha indicado que se trata de un material no prestable y que no se encuentra escaneado. Es así que los investigadores deben acudir a la biblioteca a consultarlo, independientemente de que puedan escanear puntualmente alguna página concreta y enviarla, previa solicitud al correo electrónico (informacion.bp.al.ccul@juntadeandalucia.es). En nuestro caso, la biblioteca nos ha informado sobre los fondos existentes en esta materia y nos ha facilitado escaneadas dos portadas y una contraportada. 
Caso Criminal, correspondiente al No 2058, del 20 de enero de 1990, escaneados por la Biblioteca Pública de Almería. Dichos ejemplares nos han permitido documentar contenidos, manchetas y tratamiento de las noticias.

El resto de datos que documentan y complementan este trabajo se han obtenido a través de fuentes bibliográficas y, sobre todo, búsquedas en diversas publicaciones digitales, como El País, periódico bien informado sobre Eugenio Suárez y su grupo editorial, ya que fue acogido como articulista por el fundador del Grupo PRISA (Jesús de Polanco), quien lo ayudó en sus últimos años de vida, escribiendo artículos costumbristas para el citado diario y unas colaboraciones en programas de la Cadena SER.

La aportación realizada en este trabajo ha supuesto no sólo estudiar un nuevo semanario de sucesos, del que apenas se ha investigado tanto periodística como históricamente, sino que la novedad reside en demostrar que realmente no se trató de la continuidad de El Caso, tal y como hasta la fecha se ha creído, sino de la puesta a la salida al mercado de un periódico similar, pero a su vez diferente al original de Eugenio Suárez.

\section{El 29 de agosto de 1987 desaparece El Caso}

El sábado 29 de agosto de 1987 se publicaba en Madrid el último número en concreto el 1843) de El Caso (figura 1), con un precio de venta al público de 60 pesetas el ejemplar. Periódico que, desde inicios de ese año, estaba dirigido por Joaquín Abad y como director adjunto figuraba Juan Sánchez Rada. Ya no volvió a editarse nunca más. Rada, quien ejerció en numerosas ocasiones de director en funciones, señala que el cierre del semanario fue algo inesperado, pero se vio en la quiebra total.

En su mancheta constaba como director Joaquín Abad, director adjunto Juan Sánchez $\operatorname{Rada}^{3}$ y coordinador José Vicente de Lucas y Prescres, S. A. como sociedad editora. En cuanto al equipo redaccional y de colaboradores, se encontraban Emilio Aguirre, Santiago Almarza, Pedro Avilés, Juan Ignacio Blanco, Juan Carlos de la Cal, Nicolás Cantarero, David Fernández, José Javier González, Hortensia Huerta, Carlos Iglesias, José Montoro y Marisa Pérez. La redacción y administración estaba en la calle Covarrubias $n^{\circ} 1$, en Madrid capital, y tuvo, hasta su final, una delegación en Barcelona.

3 El veterano periodista de investigación y escritor criminalista Juan S. Rada está especializado en crónica negra (roja) y misterio, policiales y casos criminales. Ha escrito varios libros sobre esta temática. 
Figuras 1 y 2: Última portada de El Caso y primera portada de El Caso Mundial.
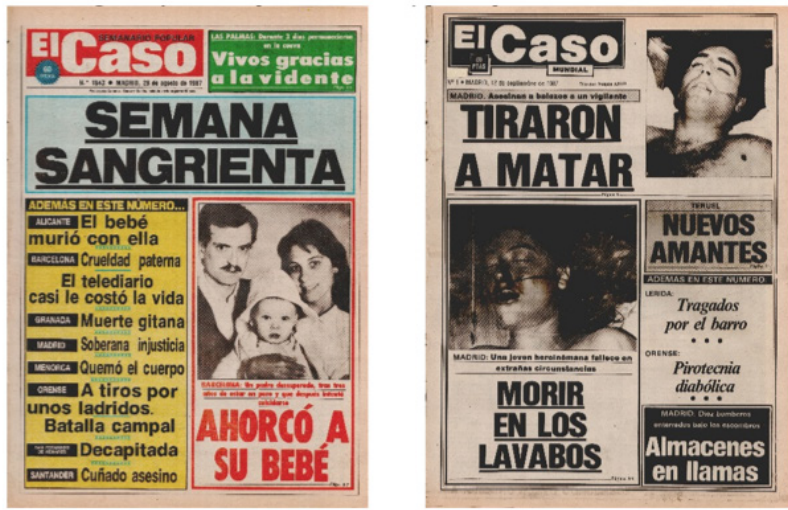

Fuentes: El Caso (No 1843, 29/VIII/1987) y El Caso Mundial (12/IX/1987).

Las causas que motivaron el cierre del periódico de sucesos de mayor éxito de la historia del periodismo español fueron tanto económicas (la competencia de otras incipientes empresas periodísticas) como derivadas de problemas familiares de Suárez. Rada explica el principal motivo que llevó a la ruina a esta mítica publicación especializada:

\footnotetext{
Pese a que vendía más de cien mil ejemplares por número, el cierre se debió a la dura pugna mantenida por su fundador y propietario, Eugenio Suárez, con José Antonio Fernández de Bobadilla (casado con una ex mujer del periodista), el cual le había dirigido desde Sábado Gráfico, otra de sus publicaciones, duros ataques por su actividad como constructor. El magistrado Clemente Auger nombró un administrador judicial para la editora. Se inició un largo rosario de litigios, embargos y acciones contenciosas. La situación se hizo insostenible. Finalmente el juzgado dio posesión de los bienes del semanario de sucesos, así como del resto de publicaciones, a María Teresa Lázaro, ex cónyuge del editor (Rada, 2019).
}

Juan Carlos Arias, que fue corresponsal de El Caso en Andalucía durante la década de 1980, añade que "el principio del fin del semanario fue la salida en 1980 de la redactora más popular del periódico, Margarita Landi” (Rodríguez, 2012: 227), quien fichó por la revista Interviú y consiguió doblar su tirada con la nueva incorporación. Landi fue contratada en noviembre de 1980 por el semanario de Ediciones Zeta como redactora de la sección de sucesos, función que desempeñó durante 8 años $^{4}$.

\section{Nuevo semanario de sucesos, editado en Almería}

El periodista, escritor, editor y sobre todo empresario Joaquín Abad (último director de $E l$ Caso en 1987) aprovechó el nicho de mercado dejado tras la desaparición de la popular

4 Margarita Landi estaba considerada como una experta en temas de investigación criminal. Colaboró en series como "Mis crímenes favoritos" en Telemadrid y "Código Uno" en TVE 1. 
cabecera para sacar al mercado un nuevo producto periodístico, parecido en formato, contenidos y nombre de la publicación. La primera edición salía impresa en Madrid el 12 de septiembre de 1987, bajo la denominación El Caso Mundial (figura 2). Juan Rada cuenta más detalles sobre su puesta en marcha:

\begin{abstract}
Abad, quien editaba desde hacía varios años en Almería el diario La Crónica, sacó al mercado el 12 de septiembre una publicación de sucesos. No tenía absolutamente nada que ver con la de Madrid, algo que yo desconocía cuando publiqué mi libro 60 Aniversario de El Caso. Creí la versión de Abad de que había adquirido los derechos sobre la misma, pero no era así. La cabecera de El Caso es, desde 1987, propiedad de Jesús Carlos Fernández Sedano, periodista de dicho semanario que la embargó a causa de salarios impagados. Por ello, Abad tuvo que crear una nueva cabecera (El Caso Mundial, que luego transformó en El Caso Criminal y después en El Caso, durante esa etapa de diez años que duró). Utilizó algunos de los reporteros del semanario cerrado en Madrid (Rada, 2019).
\end{abstract}

Por los datos recabados parece ser que Joaquín Abad nunca llegó a comprar la cabecera de El Caso, como hasta la fecha se ha divulgado en sentido contrario en diferentes medios de comunicación españoles. La cabecera quedó registrada, según informa Rada (2019), a nombre del periodista Fernández Sedano en el Registro de la Propiedad Industrial en 1987, con vistas a hacer negocio con la marca y poderla vender comercialmente, pero finalmente no se produjo la venta 5 .

El diario El País (1987a) una información en la que decía que una comisión judicial ordenada por el magistrado Jesús Nicolás García de Paredes, titular del juzgado de primera instancia número 3 de Madrid, daba posesión el 24 de septiembre de 1987 de la cabecera y bienes del semanario El Caso a María Teresa Lázaro, ex mujer del mayor accionista de esta publicación, Eugenio Suárez. Según hacía constar dicha noticia, este juez dictó en julio una resolución por la que resolvía nombrar administradora de El Caso a Lázaro y decretaba la entrega de cuentas desde 1970 y el embargo de la cabecera a favor de esta señora. Otro dato importante que añadía es que el mencionado magistrado había enviado un apercibimiento judicial a la empresa Edial, S. A. "para que se abstenga de editar e imprimir dicho periódico, así como cualquier otra publicación que tenga como base de su denominación El Caso". El 12 de septiembre de 1987 salía a la calle con el nombre El Caso Mundial $\mathrm{N}^{\mathrm{o}}$ 1, dirigido por Abad.

A raíz de divulgarse estos datos, El País (1987b) publicó al día siguiente la versión de Eugenio Suárez el cual aclaraba que el juez se había limitado a designar a María Teresa Lázaro "administradora depositaria", situación que no afectaba a la titularidad de la cabecera de El Caso, que seguía siendo aún propiedad de él (y que posteriormente pasó a manos de Fernández Sedano). La decisión del juez García de Paredes, de entregar la cabecera de El Caso a Lázaro provenía, en declaraciones de Suárez, "del impago de unos seis millones de pesetas que, en concepto de alimentos para un hijo, ya mayor de edad, adeudaba el marido

5 Jesús Carlos Fernández Sedano fue director hasta 1985, aunque siempre figuraba como "director en funciones". 
a la esposa". El País (1987b) finalizaba apuntando que Suárez asegura que "el arbitrio judicial ha designado administradora depositaria a María Teresa Lázaro, a petición de ella misma, lo que es aplicable", puntualiza, "a la situación contable y financiera de la empresa, no a la titularidad de la cabecera", que sigue, por ahora, en propiedad de Eugenio Suárez. Rada (2019) insiste en la inexactitud de la idea generalizada de que Abad comprara la cabecera de Eugenio Suárez.

\begin{abstract}
No es cierto. Lo que pasó es que Joaquín Abad quiso aprovechar el hueco dejado por la marca comercial, vio que había negocio, copió y lanzó una nueva marca parecida. Incluso un juez le envió una comunicación para que no editara con el mismo nombre. Además, la numeración del nuevo seminario no correspondía con las del original. En definitiva, fue otro producto, pero no una segunda etapa de $E l$ Caso. No tiene nada que ver (Rada, 2019).
\end{abstract}

Deducimos que si Joaquín Abad hubiera comprado la cabecera de El Caso, no habría tenido problemas para publicar, en una segunda etapa, el semanario con la denominación originaria. Por ello tuvo que editarlo en sus primeros dos años, a través de la sociedad Edial, con el nombre de El Caso Mundial (desde el 20 de mayo de 1987 al 13 de mayo de 1989) y durante más de cinco años, a través de Edicrónica, como El Caso Criminal (figura 3), del 20 de mayo de 1989 al 13 de agosto de 1994. Reseñar que los adjetivos "mundial" y "criminal" siempre aparecieron impresos con letras mucho más pequeñas que el nombre El Caso, que era lo más vistoso. Durante los casi últimos tres años de vida de la publicación (de julio de 1994 a septiembre de 1997) se vendió bajo el título de El Caso a secas (figura 4), también editado por Edicrónica. Además, hay que especificar que tanto la Biblioteca Pública de Almería como la Biblioteca Nacional de España tienen catalogados los ejemplares del periodo de 1989-1994 como El Caso Criminal, puesto que se trata de otra publicación diferente a El Caso.

Figuras 3 y 4: Portadas de El Caso Criminal y El Caso.
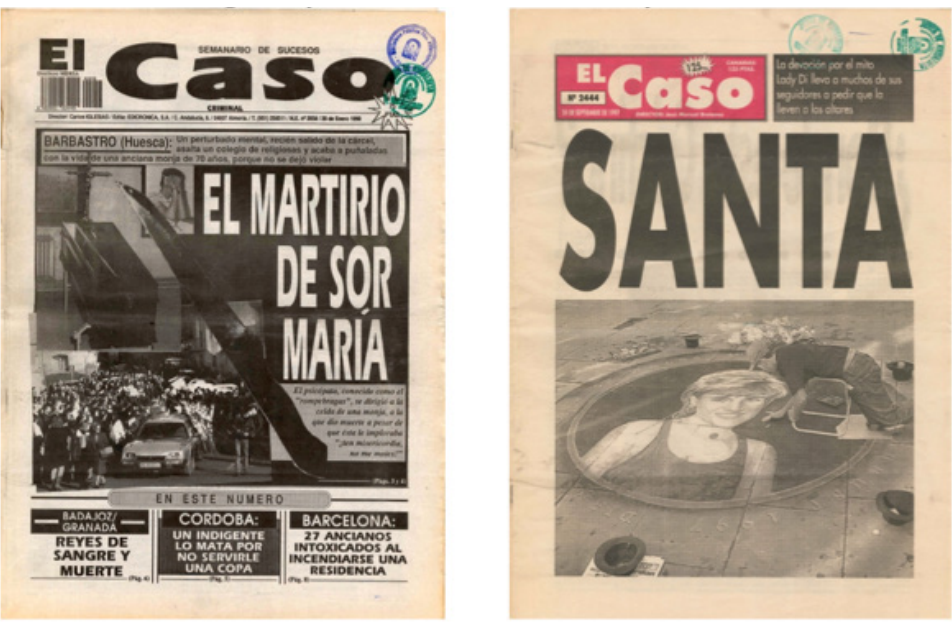

Fuentes: El Caso Criminal (No 2058, 20/I/1990) y El Caso (No 2444, 24/IX/1997). 
Joaquín Abad, propietario del nuevo semanario cuyos primeros ejemplares se hicieron desde Madrid, trasladó pronto la redacción y los talleres a su ciudad natal, Almería, donde los costes eran más económicos, aunque la distribución a nivel nacional era de mayor complejidad. En la mancheta de El Caso Mundial constaba como editora Edial S. A. La fotocomposición e impresión se ejecutaba en los talleres de Almería de Comunicaciones S. A., según recogemos del ejemplar impreso el 3 de octubre de 1987. También figuraba una secretaria de dirección, María Jesús Gómez, y como redactores aparecían los nombres de Ramón Arangüena, Inés Arribas, Enrique Díaz, Pilar Díaz, Carlos Cortés, José María Latorre, Lorena Sánchez y Rubén Adrián Valenzuela. Se trata de una plantilla diferente a la de El Caso, excepto Pedro Avilés, Juan Ignacio Blanco y José Montoro que provenían del semanario de Eugenio Suárez. Tenía, además, una redacción en Madrid.

En 1989 aparece José Manuel Bretones como redactor jefe, siendo responsable de las denominadas "Secciones y Concursos" Carlos Iglesias. La redacción se hallaba ubicada en la calle Andalucía, 8. Disponía de delegaciones en Madrid (integrada por los ya citados Pedro Avilés, Ramón Arangüena, y José Montoro, además de nuevos periodistas como José Javier González Paz y Belén Seaone) y en Barcelona (compuesta por Rubén Adrián Valenzuela y Juan Giner).

Posteriormente, en la década de 1990, Edicrónica S. A. (la nueva sociedad editora, con sede en Almería capital) sacaba también periódicos como La Crónica o La Voz del Ejido y otras publicaciones. Se distribuía el semanario de sucesos de Abad a toda España desde la capital almeriense, utilizando la rotativa de La Crónica. En 1992 nombraron director de El Caso Criminal a José Manuel Bretones, el cual ya había sido director en funciones y subdirector de otros diarios locales de Edicrónica.

En 1992, al regresar de la "mili" [servicio militar] me propusieron dirigirlo al mismo tiempo que otras publicaciones de la editorial. Anteriormente, habían sido directores el propio Abad y Carlos Iglesias, periodista este último que trabajó con Eugenio Suárez y se vino a Almería, llevando la sección de "Tribunales", pero fue posteriormente despedido (Bretones, 2019).

Abad fue también director en Almería, desde el 28 de julio de 1982, del diario independiente La Crónica, que entabló una dura batalla contra la mafia local, encabezada por Juan Asensio, capo que durante 1980 y 1990 controló dicha ciudad y fue asesinado en 2014 en el ascensor de su vivienda. El periódico dejó de imprimirse el 30 de noviembre de 1998. Así lo contaba:

Fui director de El Caso desde que el anterior editor Eugenio Suárez me llamara en el año 1987. Yo dirigía un aguerrido diario en Almería, La Crónica, que se había hecho famoso porque no paraba de levantar exclusivas y se había enfrentado a la mafia local, lo que le valió bombas, incendios en sus instalaciones, amenazas (Abad, 2016, p. 2).

Abad compatibilizó, por tanto y no sin dificultades, tanto la gestión empresarial como la dirección de dos periódicos desde 1987 a 1992. Uno de carácter local y de información general (La Crónica de Almería) y otro de ámbito nacional y especializado en sucesos, como El Caso Mundial / El Caso Criminal. Todo un reto periodístico y empresarial. 


\section{Estilo y línea informativa}

El estilo y la línea informativa del periódico de sucesos de Joaquín Abad estuvieron influenciados, tanto en el contenido (primaban los crímenes), diseño (portadas impactantes con grandes titulares sensacionalistas y fotos muy realistas) y formato (35 x 29), por $E l$ Caso de Eugenio Suárez, ya que marcó un estilo propio y característico de la información de sucesos durante 35 años. También salía a la calle los sábados e incluso el número de páginas de ambos semanarios era el mismo: un total de 16.

Desde un enfoque histórico, la diferencia fundamental reside en que durante 23 años el semanario de Suárez se publicó en la dictadura del general Franco (teniendo que sortear alguna que otra censura, en especial había que tener cuidado con las imágenes o los contenidos de tipo sexual, aunque fue su época de mayor éxito de ventas) y durante los doce años restantes en otro régimen político de transición y democracia. El periódico de Abad se imprimió durante una década sin el inconveniente de la censura política, en plena democracia (se publicaban incluso fotos de desnudos en sus páginas), pero surgieron otros problemas que, como ya veremos, motivaron su ocaso.

Bretones (2019) menciona que las diferencias entre ambos periódicos vienen marcadas por el paso de los tiempos, ya que no era lo mismo una redacción de 1969 que la del año 1993, al igual que en el caso de los archivos, la técnica o la formación de los profesionales.

El Caso de Eugenio Suárez tenía la cortapisa de la censura, pero la fortuna de una policía que le ayudaba, unos enterradores que facilitaban la información y unos lectores fieles, jóvenes y seguidores al cien por cien. Mucha gente aprendió a leer con el semanario, a pesar de la mala fama que tenía como el periódico “de las porteras”. Además, tenía una redacción profesional y muy motivada (Bretones, 2019).

Desde el punto de vista periodístico, al igual que hacía la cabecera originaria, el semanario impreso en Almería intentaba abrir siempre con un crimen y una fotografía principal acompañada (o no) por el pie de foto y un gran titular muy impactante. Además de los asesinatos, se informaba de todo tipo de delitos, así como de sucesos sorprendentes y se publicaban fotos sensacionalistas. También se empleaban dibujos e ilustraciones, que servían para explicar gráficamente algunos de los sucesos de mayor transcendencia. En sus páginas interiores se publicaban sucesos muy variados, redactados en forma de crónicas y reportajes.

Bretones (2019) confirma que los crímenes eran los sucesos más importantes para publicar en el semanario, la mayor parte de la información giraba sobre esta temática y siempre se intentaba abrir la portada con estos graves delitos. No obstante, matiza, había lugar para noticias internacionales, reportajes esotéricos, crónica de tribunales y algunos reportajes sociales que afectaban a los niños. "Sin duda, las muertes violentas eran el trabajo fundamental de la redacción, lo que la editorial quería y lo que los lectores buscaban y por eso nos compraban" (Bretones, 2019).

Durante los casi dos años que se imprimió el semanario bajo la cabecera de El Caso Mundial (septiembre 1987 - mayo 1989) primaban las informaciones sobre asesinatos. 
La portada del número 1 abría, de forma destacada, con dos sucesos violentos: "Madrid. Asesinan a balazos a un vigilante. Tiraron a matar" y "Madrid: Una joven heroinómana fallece en extrañas circunstancias. Morir en los lavabos". Los titulares de ambas noticias iban acompañadas por dos grandes fotografías de las víctimas ensangrentadas. El resto de titulares que aparecían, a menor tamaño, eran los siguientes: "Teruel. Nuevos amantes", "Lérida: Tragados por el barro", "Orense: Pirotecnia diabólica" y "Madrid: Diez bomberos enterrados bajo los escombros. Almacenes en llamas" (figura 2).

También se publicaban noticias sobre otros delitos (violaciones, secuestros, entre otros). Había una sección de "Tribunales" (coordinada por Carlos Iglesias, que ocupaba dos páginas) y también otra denominada "Sucesos mundiales", ocurridos en el extranjero. Asimismo, tenían cabida hechos sobre terrorismo (ETA, IRA), sucesos curiosos ("Niño, mordido por un murciélago rabioso", "Aterrizó en una autopista" o "Pescaron un submarino", titulares publicados en el No 6 del 3 de octubre de 1987), de denuncia social, asuntos relacionados con los famosos ("Lola Flores se defiende. Reacción de La Faraona ante lo publicado la semana pasada" o "Sara Montiel, salpicada por un crimen", titulares aparecidos en el $\mathrm{N}^{0} 78$, del 4 de marzo de 1987) o incluso fotos de mujeres desnudas o semidesnudas (aparecían en la sección "La chica Mundial” o en la contraportada).

Primaban las crónicas y reportajes de interpretación, no existían propiamente editoriales, pero sí algunos comentarios recuadrados. Así arrancaba una crónica firmada a doble página por Pedro Avilés y titulada "Papá: mamá está muerta en el desván" (se había publicado también en portaba con letras en rojo: "Velaron seis meses el cadáver de su madre"):

\footnotetext{
Muchas veces se nos dice que las historias que publicamos en nuestro semanario parecen inventadas. Nada más lejos de la realidad. Este es el caso, con todos los componentes de una película de terror peculiar de Hitchcock, el famoso director de Psicosis acontecido en la leridana localidad de Cervera. Allí, tres hermanos daneses, Jack, de 18 años, Dea de 16, y Helga de 14 han protagonizado un sucesos de proporciones misteriosas que ha dejado con la boca abierta a todo el pueblo y a todos cuantos han tenido conocimiento del asunto: los tres jóvenes han sido capaces de convivir junto al cadáver de su madre por espacio de casi seis meses en la antigua y tétrica casa que la familia posee en Cervera. No se trata de un asesinato ( ${ }^{\circ} 4,3 / \mathrm{X} / 1987$, pp. 6-7).
}

Con respecto a El Caso Criminal (se imprimió durante más de 5 años, de mayo de 1989 a agosto de 1994), el mismo nombre de la cabecera ya indicaba su línea informativa. A principios de 1990 estaba dirigido por Carlos Iglesias, periodista de amplia experiencia profesional que fue redactor de El Caso, de Eugenio Suárez. A partir de 1992 cambia de director y se nombra a José Manuel Bretones. La portada del 20 de enero de 1990 (figura 3) estaba dedicada casi en su totalidad a un asesinato cometido contra una religiosa. La composición de la primera página, a modo de fotomontaje, era muy llamativa, con un gran titular en mayúsculas: "El martirio de Sor María" y, de fondo, las fotos del asesino, del féretro dentro del coche fúnebre y la imagen de un gran cuchillo ensangrentado. El subtítulo figuraba así: "Barbastro (Huesca): Un perturbado mental, recién salido de la cárcel, asalta un colegio de religiosas y acaba a puñaladas con la vida de una anciana monja de 70 años, porque no se dejó violar". Dicha información ocupó al completo las páginas 2 y 3 . El resto de noticias 
que se incluían en la portada se anunciaban (a menor tamaño y en la parte inferior) con los titulares: "Badajoz/Granada. Reyes de sangre y muerte", "Córdoba: Un indigente lo mata por no servirle una copa" y "Barcelona: 27 ancianos intoxicados al incendiarse una residencia" (figura 3).

Los últimos tres años de existencia del periódico (de agosto de 1994 a septiembre de 1997) apareció con el nombre de El Caso. A partir de mayo de 1997 pasó a ser de periodicidad quincenal, según se hace constar en la ficha de catalogación de la Biblioteca Pública de Almería. Su director era José Manuel Bretones. La portada de su último número (2444) correspondiente al 24 de septiembre de 1997, curiosamente no estuvo ocupada por un crimen, sino por una temática de "crónica rosa". Un gran título en mayúsculas, "Santa" y amplia foto de Diana de Gales llenaban al completo la primera página, en donde sólo había espacio para un pequeño recuadro en la parte superior derecha con el siguiente antetítulo: "La devoción por el mito Lady Di lleva a muchos de sus seguidores a pedir que la lleven a los altares" (figura 4). No obstante, su contraportada sí siguió fiel a sus contenidos tradicionales, ya que incluía una crónica titulada "Gloria María quería dos hombres" con el antetítulo: "Madrid: La doble relación amorosa que mantenía una mujer acabó, a causa de los celos, en el intento de asesinato de un novio hacia el otro hombre" e ilustrada por un gran dibujo.

Como vemos, este periódico siguió la pauta marcada por El Caso a partir de 1970, ampliando sus contenidos informativos más allá de los sucesos e incorporando las denominadas "noticias del corazón", la crónica social y los hechos pintorescos. El estilo de este semanario, como ocurría con el de Suárez, era popular y sensacionalista, sobre todo por su presentación formal (grandes titulares de color rojo y fotos realistas o escabrosas), pero no puede considerarse amarillista, puesto que no inventaba las noticias, ya que difundía la realidad más cruda e increíble y sus corresponsales y redactores lo contaban con un estilo claro, directo y políticamente incorrecto. Bretones (2019) explica la línea informativa que seguía y la organización del trabajo periodístico:

\footnotetext{
Durante mi época de director la línea informativa era la ya conocida por los lectores, pero evolucionando a unos reportajes escritos con más calidad literaria. Es evidente que siempre se abría con un suceso, si no del que mejor material había sí el más impactante, exclusivo o mejor elaborado. Nosotros teníamos una redacción central en Almería, una red de corresponsales en las principales ciudades y dos equipos móviles que se trasladaban desde la ciudad almeriense al lugar del crimen para trabajarlo e investigarlo. Luego regresaban a Almería a escribir y a positivar las fotos. En Almería estaban los diseñadores y editores (Bretones, 2019).
}

El semanario no incluía muchos anuncios, prevaleciendo los contenidos informativos (texto e imágenes) con una composición muy llamativa, titulares de color rojo, a gran tamaño, y un estilo de lectura próxima a los lectores. 


\title{
6. Causas de su desaparición
}

La segunda etapa de El Caso fue más corta y duró diez años. Durante una década, Abad luchó por mantener a flote un periódico que no ganaba dinero por publicidad, sino por venta, según su propietario. Revisando algunos de los ejemplares de El Caso Mundial y El Caso Criminal, se constata que los anuncios eran poco numerosos. A pesar de ser rentable (llegó a vender 120000 ejemplares por número), el incremento de los costes y las numerosas demandas, reclamaciones judiciales y pleitos que le interponían, provocaron el cierre definitivo del periódico. El 24 de septiembre de 1997 se imprimió por última vez.

Abad (2016) ha comentado públicamente que una de las razones de que se dejara de publicar fue por el coste económico que suponían los pleitos, la mayoría por vulneración del derecho o el honor de criminales, que eran ganados en la mayoría de los casos por el periódico, pero las costas judiciales no eran devueltas al tratarse de delincuentes. Así explicaba Abad a la Asociación de la Prensa de Madrid (APM), que se cerró porque el Departamento Nacional de Justicia había transferido sus competencias a las autoridades regionales o autonómicas ${ }^{6}$.

\begin{abstract}
Antes, cuando alguien sentía vulnerado su derecho al honor, nos denunciaba al juzgado de Madrid, donde estaba la redacción y solíamos ganar casi siempre. Teníamos en plantilla a los abogados. Cuando empezaron las autonomías a hacerse cargo de estas demandas, nos obligaban a ir a los distintos sitios correspondientes de España. Era molesto sacar El Caso en ese momento. Teníamos que ir a muchas ciudades a defendernos. Se ganaba dinero, pero no mucho porque teníamos una estructura muy grande (APM, 2016).
\end{abstract}

Rada (2019) considera que hubo una mala gestión empresarial porque "creaba una sociedad y la disolvía por deudas, creaba otra y así sucesivamente, amontonando deudas, como es el caso de las sociedades anónimas Edial y Edicrónica". Su último director, José Manuel Bretones, aporta otros motivos que provocaron su desaparición. Pese a que el semanario era rentable (se tiraban más de 50000 ejemplares en 1997 y tenía muchas suscripciones) las dificultades en la distribución, el incremento del coste del papel y el crimen de las tres niñas de Alcácer (que les hizo bajar mucho las ventas) provocaron el cierre definitivo (Rodríguez, 2016, p. 41).

Bretones (2019) también añade errores de estrategia empresarial: aunque el semanario generaba ingresos y permitió la publicación de otras cabeceras deficitarias del grupo (Universo secreto, otra dedicada a personas desaparecidas y varias más), la realidad era que, por un lado, se ganaba lo mismo y, por otro, se perdía dinero. No se invertía, porque

6 La construcción del Estado de las autonomías fue un proceso por el cual las regiones y nacionalidades de España accedieron a la autonomía tras la promulgación de la Constitución Española de 1978. Comenzó en 1979 y acabó en 1995. Se crearon 17 comunidades autónomas, 2 ciudades autónomas (Ceuta y Melilla) y 1825 entidades locales. Ello provocó una descentralización administrativa y judicial. Este reconocimiento de la autonomía territorial jurídica y administrativamente se materializa en una profunda descentralización hasta el punto de que el funcionamiento efectivo del Estado español se asemeja al propio de los Estados federales. 
ya no era tan rentable como antes, aunque se seguían vendiendo muchos ejemplares con un coste elevado del papel. Probablemente, si se hubieran realizado más inversiones, los costes habrían bajado y aguantado el periódico unos años más. En cuanto a la redacción, estaba amortizaba, ya se utilizaban ordenadores, siendo la primera que disponía de Macintosh.

\begin{abstract}
Las dificultades en la distribución desde una esquina de España a todo el Estado, el incremento del coste del papel y otras cuestiones internas de la editorial deterioraron el producto y terminó por dejar de salir. En mi caso, aunque teníamos una redacción súper profesional, mejores medios técnicos o más opciones informativas, los lectores iban muriendo, la empresa editora no mimó como hubiésemos querido a la publicación buscando nuevos horizontes y había una competencia feroz en otras revistas de información general, en las teles y en los propios periódicos (Bretones, 2019).
\end{abstract}

En efecto, la distribución desde Almería ${ }^{7}$ fue uno de sus grandes inconvenientes, ya que sus comunicaciones eran muy deficitarias. El hecho de distribuir un periódico desde Madrid era una de las ventajas de la que disfrutaba El Caso de Suárez. En cualquier caso, desde el principio Joaquín Abad apostó por esta ciudad española, ya que la impresión era mucho más económica, aunque la distribución fuera más cara.

\footnotetext{
“Alcácer" marcó un antes y un después en la información de sucesos en España [...] Después del espectáculo lamentable que montaron los espacios televisivos (porque aquello no era información), hubo una cerrazón de las autoridades, policías y gobiernos civiles a facilitar información de sucesos. Antes éramos cómplices, en muchas ocasiones, para la investigación policial, pero desde "Alcácer" éramos enemigos. Desde entonces, el semanario comenzó a bajar de venta porque no podíamos salir a la semana con lo que habían machacado días antes las televisiones. En algunas publicaciones, desde "Alcácer", dejaron de publicar suicidios [...] y hasta eliminaron el cintillo de "Sucesos" para poner cobardemente "Sociedad" (Bretones, 2019).
}

Por último, hay que anotar que muchos de los lectores de este semanario eran los que anteriormente había tenido El Caso. Lectores fieles que gustaban de un periódico similar al creado por Suárez. Se trataba de un público cada vez más envejecido, donde existió escasa renovación generacional de sus seguidores, ya que los jóvenes lectores compraban otro tipo de publicaciones, algo lógico, puesto que la sociedad española había cambiado.

Después de la desaparición de El Caso, editado en Almería, Abad (2016) puso en marcha en 2014 una edición digital del semanario, bajo el dominio elcaso.net, pero sin lograr buenos resultados. Fue una iniciativa en Internet para probar, ya que disponía de un editor

7 La ciudad de Almería y su provincia pertenece a la región o comunidad autónoma de Andalucía, situada al sur de España. En concreto pertenece a la denominada Andalucía occidental y sus costas dan al Mar Mediterráneo. Uno de sus carencias más evidentes son las comunicaciones, aunque con el paso del tiempo han ido mejorando.

8 Se trata del secuestro, violación, tortura y asesinato de Miriam, Toñi y Desiré, tres adolescentes de 14 y 15 años del municipio valenciano de Alcácer, España. Desaparecieron el 13 de noviembre de 1992 y el 27 de enero de 1993 encontraron sus cadáveres semienterrados junto al pantano de Tous (Valencia). Los asesinos fueron Antonio Anglés y Miguel Ricart. 
de periódicos ya programado. Se trataba de otro producto periodístico, apostando por las nuevas tecnologías y enfocado también al público hispanoamericano.

El 22 de abril de 2016 salía al mercado español El Caso, bajo el subtítulo "semanario de sucesos”, editado por El Caso del Siglo XXI, S .L. y dirigido por Joaquín Abad. Impreso en Madrid y con una tirada de más de 100000 ejemplares, aprovechando nuevamente la marca comercial del semanario de Eugenio Suárez, a raíz de la emisión de Televisión Española (TVE) de la serie “El Caso. Crónica de sucesos". La publicación aparecía con una edición renovada en formato revista, tamaño bolsillo y a todo color. Estaba disponible cada viernes en los kioscos a un precio de 2,50 euros y acompañada con un facsímil de los ejemplares más destacados tanto de El Caso de Suárez como del semanario editado por Abad. Esta nueva iniciativa empresarial duró 13 números. En la "Carta del director", firmada por Abab (2016), aclaraba que relanzaba un nuevo El Caso.

\footnotetext{
Hace veinte años cerramos la edición impresa de un El Caso clásico porque entendimos que era el momento de cerrar una etapa. Continuó en Internet y en formatos digitales contando crímenes de América del Sur, mucho más horribles que los españoles, por supuesto. Ahora que volvemos a relanzar un nuevo El Caso, me encuentro con historias que no son muy diferentes de las que se daban hace 30 , 40 años. Los que están cercanos al poder, los ricos, los conectados con Zarzuela, con ministros, se creen blindados y cometen fechorías sin temor a pisar la cárcel (Abad, 2016: 2).
}

Dejó de imprimirse en papel, pero continúa en formato digital, bajo el dominio ya creado de elcaso.net (https://www.elcaso.net/) y con las secciones "Nacional", "Mundo Insólito" y "El Caso Hispano" (informa de la nota "roja" o "policial" de los países de Hispanoamérica). Abad actualmente es el fundador y presidente ejecutivo de la empresa Cibeles Group, LLC, que tiene a su cargo publicaciones y sedes en España y EE. UU. Es miembro de la AEEPP (Asociación Española de Publicaciones) y presidente de la Asociación Española de Publicaciones Digitales. También es director del periódico digital mil21.es.

\section{Fuentes consultadas}

Abad, J. (22 de abril de 2016). Carta del director. El Caso, núm. 1, Madrid.

Asociación Española de Editoriales de Publicaciones Periódicas, AEEPP (1 de octubre de 2014). Semanario "El Caso". Recuperado de https://www.aeepp. com/noticia/1621/noticias-asociados/semanario-el-caso.html.

Asociación de la Prensa de Madrid, APM (29 de abril de 2016). Joaquín Abad: "El Caso" ya no puede dar noticias, lo que tiene que hacer es profundizar en los temas. Recuperado de https://www.apmadrid.es/joaquin-abad-el-caso-ya-nopuede-dar-noticias-lo-que-tiene-que-hacer-es-profundizar-en-los-temas/

Bernaldo de Quirós, R. (10 de junio de 2014). Joaquín Abad, periodista de combate Recuperado de https://joaquinabad.es/noticia/702/sociedad/joaquin-abad-periodista-de-combate.html 
Biblioteca de Almería (2019). Portal oficial. Recuperado de http://www.bibliotecasdeandalucia.es/web/biblioteca-del-estado-publicaprovincial-de-almeria

Bretones, J. (22 de abril de 2019). Director de El Caso Criminal (1992-1997). Entrevistadora: Rosa Rodríguez Cárcela.

Caño, J. (31 de diciembre de 2014). Eugenio Suárez, el editor genial. Muere el periodista que fundó el semanario "El Caso" y "Sábado Gráfico". Recuperado de https://elpais.com/cultura/2014/12/31/actualidad/1420038110_541956.html

El Caso (1987). Ediciones del 4 de julio y 29 de agosto de 1987. Madrid, España.

El Caso (1997). Edición del 24 de septiembre de 1997. Almería, España.

El Caso (2019). Portal de El Caso. Semanario de sucesos. Recuperado de https://www.elcaso.net/

El Caso Criminal (1990). Edición del 20 de enero de 1990. Almería, España.

El Caso Mundial. Ediciones del 12 de septiembre (Madrid) y 3 de octubre (Almería) de 1987. España.

El País (1987a). Cambia la titularidad de "El Caso" y "Velocidad” por decisión judicial. Recuperado de https://elpais.com/diario/1987/09/25/sociedad/559519208_850215.html

El País (1987b). Eugenio Suárez afirma que sigue siendo el propietario de "El Caso" y "Velocidad". Recuperado de https://elpais.com/diario/1987/09/26/sociedad/559605605_850215.html

Rada, J. (7 de mayo de 2019). Director de El Caso, de Eugenio Suárez, en su etapa final. También ejerció de redactor, director adjunto y director en funciones. Entrevistadora: Rosa Rodríguez Cárcela.

Rodríguez Cárcela, R. (2012). El Caso. Aproximación histórico-periodística del semanario español de sucesos. Correspondencias \& Análisis, n ${ }^{0}$ 2, 219-235. doi: 10.24265/cian.2012.n2.11

Sanz, D. (23 de abril de 2016). La televisión da otra vida a “El Caso”. Recuperado de https://www.elmundo.es/television/2016/04/23/571a777246163f471b8b4654.html 